\title{
Clinical Significance of Continuable Treatment with Nintedanib Over 12 Months for Idiopathic Pulmonary Fibrosis in a Real-World Setting
}

This article was published in the following Dove Press journal: Drug Design, Development and Therapy

\author{
Motoyasu Kato $\mathbb{D}^{1}$ \\ Shinichi Sasaki ${ }^{1,2}$ \\ Misa Tateyama' \\ Yuta Arai ${ }^{1}$ \\ Hiroaki Motomura' \\ Issei Sumiyoshi' \\ Yusuke Ochi' \\ Junko Watanabe' \\ Hiroaki lhara (iD) \\ Shinsaku Togo' \\ Kazuhisa Takahashi ${ }^{1}$ \\ 'Department of Respiratory Medicine, \\ Juntendo University Graduate School of \\ Medicine, Tokyo, Japan; ${ }^{2}$ Department of \\ Respiratory Medicine, Juntendo \\ University Urayasu Hospital, Urayasu \\ Chiba, Japan
}

\begin{abstract}
Purpose: The INPULSIS-ON study suggested the safety and tolerability of long-term nintedanib treatment for idiopathic pulmonary fibrosis (IPF). However, there are no realworld studies on long-term nintedanib treatment. The main aim of the study was to investigate the efficacy and the tolerability of long-term treatment with nintedanib for IPF in clinical practice.
\end{abstract}

Patients and Methods: This retrospective study enrolled 104 IPF patients who underwent treatment with nintedanib. Among these patients, 51 were able to receive nintedanib for more than 12 months (ie, treatment with nintedanib over 12 months was possible [P group]) and 53 were not able to receive nintedanib for more than 12 months (ie, treatment with nintedanib over 12 months was impossible [I group]). The tolerability and efficacy of nintedanib were compared between the two groups.

Results: In the I group, 29 patients were unable to continue nintedanib therapy because of adverse effects, including diarrhea and nausea/anorexia. In addition, 19 and four patients could not continue nintedanib treatment because of IPF progression and worsening of performance status (PS), respectively. One patient suddenly died during nintedanib treatment. The incidence of nausea/anorexia in the I group was significantly higher than in the P group (49.06 vs $25.49 \%$ ). The survival time was significantly longer in the $\mathrm{P}$ group than in the I group (35 vs 12 months). The decline in forced vital capacity was significantly larger in the I group than in the P group (165 vs $10 \mathrm{~mL} /$ year). Poor PS at nintedanib initiation was the only significant risk factor for nintedanib treatment discontinuation over 12 months. Finally, the survival time was significantly longer in patients with good PS than in those with poor PS (27 vs 13 months).

Conclusion: Poor PS can result in discontinuation of nintedanib after 12 months. Long-term nintedanib treatment may be effective for survival.

Keywords: idiopathic pulmonary fibrosis, nintedanib, real-world setting, performance status, nausea

\section{Introduction}

Nintedanib is one of the anti-fibrotic agents used to treat patients with idiopathic pulmonary fibrosis (IPF). The INPULSIS trial demonstrated that nintedanib decreases the annual forced vital capacity (FVC) decline and acute exacerbations in IPF patients, and prolongs the time to first acute exacerbation development since nintedanib initiation. ${ }^{1-4}$ In later reports, the INPULSIS-ON study and the extension study from the TOMORROW trial (phase 2 study of nintedanib for IPF) suggested the safety and tolerability of long-term nintedanib treatment for IPF. ${ }^{1,5-7}$ Although
Correspondence: Motoyasu Kato Department of Respiratory Medicine, Juntendo University, Graduate School of Medicine, 3-I-3 Hongo, Bunkyo-Ku,

Tokyo I| 3-843I, Japan

Tel $+81-3-5802-1063$

Fax +8I-3-5802-16I7

Email mtkatou@juntendo.ac.jp
Drug Design, Development and Therapy 2021:15 223-230 
the INPULSIS trial compared the effect of nintedanib treatment between continuation of treatment after the INPULSIS trial and new nintedanib initiation after placebo treatment, there was no evaluation of survival, efficacy, and tolerability between possible and impossible continuation of nintedanib treatment. Recently, the tolerability and efficacy of long-term treatment with two anti-fibrotic agents, nintedanib and pirfenidone, have been reported. ${ }^{8}$ However, these two anti-fibrotic agents have different mechanisms of action and adverse effects. ${ }^{2,9-11}$ Moreover, although data on the safety, tolerability, and risk factors of 1-year nintedanib treatment in a real-world setting have been reported, ${ }^{12,13}$ there have been no realworld studies on long-term nintedanib treatment. Thus, in this study, we aimed to evaluate the efficacy and tolerability of long-term nintedanib treatment, particularly continuable treatment with nintedanib over 12 months, for IPF in the real-world setting. Here, we describe the characteristics of patients with IPF who were able to continue receiving nintedanib for more than 12 months; the efficacy of treatment with nintedanib over 12 months; and the risk factors associated with nintedanib treatment discontinuation within 12 months.

\section{Methods}

\section{Study Population}

We retrospectively collected the data of IPF patients who initiated treatment with nintedanib at Juntendo University Hospital and Juntendo University Urayasu Hospital between April 2015 and December 2018. IPF was diagnosed based on the international IPF diagnosis guidelines published in 2011. ${ }^{14}$ Patients who were able to receive nintedanib for more than 12 months were classified into the $\mathrm{P}$ group (ie, those for whom treatment over 12 months was possible) and patients who were not able to receive nintedanib over 12 months were classified into the I group (ie, those for whom treatment over 12 months was impossible). The study protocol was approved by the Juntendo University Ethical Committee and registered under number 18-056. The Ethical Committee waived the requirement for informed consent because of the retrospective nature of the study.

\section{Clinical Evaluation}

At the initiation of nintedanib treatment, we collected the patient's clinical data, including age, sex, smoking history, body height, body weight, body mass index (BMI), body surface area (BSA), and performance status (PS) as indicators of their general condition, and modified Medical Research Council Dyspnea (mMRC) scale score for dyspnea evaluation. ${ }^{15}$ The general condition of patients was evaluated by the Eastern Cooperative Oncology Group/ World Health Organization PS statement, ${ }^{16}$ with a PS of $>2$ representing a poor general condition. BMI was measured by dividing body weight by the square of body height. BSA was calculated by the Du Bois method. ${ }^{17}$ To determine the severity of IPF, the GAP index was calculated by age, sex, FVC, and diffusivity. A GAP index over 6 was considered severe IPF. ${ }^{18}$ We also evaluated FVC at $12( \pm 3)$ months after the initiation of nintedanib treatment. Moreover, any side effects were determined according to the Common Terminology Criteria for Adverse Events ver. 4.0 every 6 months after initiation of nintedanib.

\section{Statistical Analysis}

Fisher's exact test, the chi-square test, and the Wilcoxon two-sample test were used to investigate the incidence of side effects and to compare differences in the patients' characteristics and treatment tolerability and efficacy between the $\mathrm{P}$ group and the I group. Non-parametric and parametric data were compared by the MannWhitney $U$-test and Student's $t$-test, respectively. Differences in median survival times (MST) were analyzed using the Log rank test. The characteristics of patients in the $\mathrm{P}$ group were analyzed by multivariate analysis. Cox proportional analysis was used to evaluate the hazard ratios (HRs), and univariate and multivariate logistic regression analyses were used to establish the risk factors for nintedanib discontinuation after 12 months. A $p$-value less than 0.05 was defined as statistically significant. All statistical analyses were performed by SPSS version 26.0 for Windows (Chicago, IL, USA).

\section{Results}

\section{Patient Characteristics}

Among the 104 patients with IPF enrolled in the study, 51 patients were able to receive nintedanib for more than 12 months (patients for whom treatment over 12 months was possible, $\mathrm{P}$ group) and 53 patients were not able to receive nintedanib for more than 12 months (patients for whom treatment over 12 months was impossible, I group) (Figure 1). In the I group, 29 patients were unable to continue receiving nintedanib because of adverse effects, including diarrhea and nausea/anorexia. In addition, 


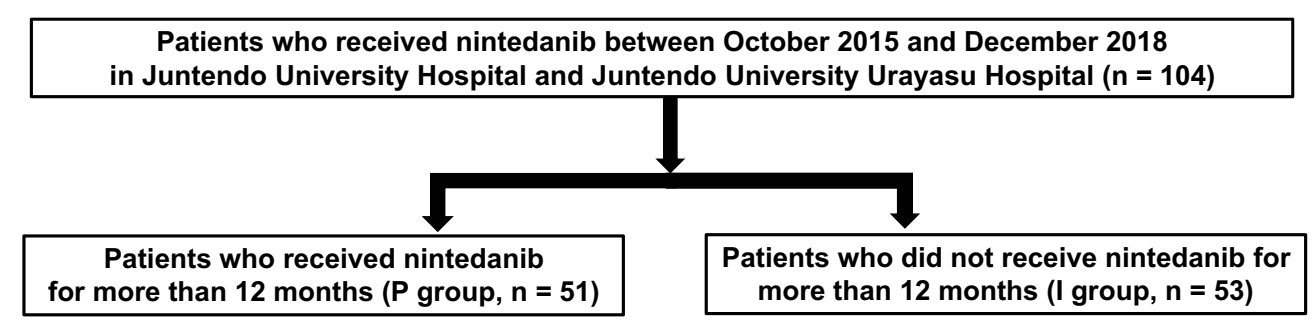

Figure I Flowchart of patient selection and allocation.

18 and four patients could not continue nintedanib treatment owing to IPF progression and worsening PS, respectively. One patient suddenly died during treatment with nintedanib. The patients' characteristics are demonstrated in Table 1. The median age of all patients was 73 (range: 62-85) years. There were 90 (86.54\%) men, 91 (87.50\%) smokers, and 24 (23.08\%) patients had poor PS. The median BMI and median BSA were $22.8 \mathrm{~kg} / \mathrm{m}^{2}$ and $1.68 \mathrm{~m}^{2}$, respectively. The median $\mathrm{FVC}, \% \mathrm{FVC}$, diffusing capacity of the lungs for carbon monoxide (DLco), and \%DLco were $2.23 \mathrm{~L}, 66.9 \%, 7.19 \mathrm{~mL} / \mathrm{min} / \mathrm{mmHg}$, and $29.81 \%$, respectively (Table 1). Eleven patients did not undergo pulmonary function testing due to a past history of pneumothorax/ mediastinal emphysema or severe cough. Among the patients who underwent pulmonary function testing, 12 patients could not test the diffusing capacity for carbon

Table I Patients' Characteristics

\begin{tabular}{|c|c|c|c|c|}
\hline Characteristics & $\begin{array}{l}\text { All Patients } \\
n=104\end{array}$ & $\begin{array}{l}\text { P Group } \\
n=51\end{array}$ & $\begin{array}{l}\text { I Group } \\
n=53\end{array}$ & $p$-value \\
\hline Age in years, median (range) & $73(46-87)$ & $70(46-87)$ & $74(5 I-87)$ & 0.056 \\
\hline Sex, men (\%) & $90(86.54 \%)$ & $46(90.20 \%)$ & $44(83.02 \%)$ & 0.391 \\
\hline Smoking history, yes (\%) & 91 (87.50\%) & $44(86.27 \%)$ & 47 (88.68\%) & 0.773 \\
\hline Performance status, $0 / 1 / 2 / 3 / 4$ & $31 / 49 / 17 / 6 / 1$ & $23 / 25 / 2 / 1 / 0$ & $8 / 24 / 15 / 5 / 1$ & 0.0003 \\
\hline $\mathrm{BMI}$ in $\mathrm{kg} / \mathrm{m}^{2}$, median (range) & $22.8(13.6-34.1)$ & $23.3(15.1-29.7)$ & $22.6(13.6-34.1)$ & 0.232 \\
\hline BSA in $\mathrm{m}^{2}$, median (range) & $1.68(1.21-2.03)$ & $1.71(1.23-1.93)$ & $1.63(1.21-2.03)$ & 0.126 \\
\hline GAP index, 0-5/6-9 & $\begin{array}{l}50 / 43 \\
n=93\end{array}$ & $\begin{array}{l}29 / 21 \\
n=50\end{array}$ & $\begin{array}{l}21 / 22 \\
n=43\end{array}$ & 0.412 \\
\hline $\mathrm{mMRC}, \mathrm{I} / 2 / 3 / 4$ & $57 / 28 / 12 / 7$ & $31 / 15 / 4 / 1$ & $26 / 13 / 8 / 6$ & 0.345 \\
\hline Nintedanib initiation dose, $300 \mathrm{mg} / 200 \mathrm{mg}$ & $65 / 39$ & $33 / 18$ & $32 / 21$ & 0.648 \\
\hline Prior PSL treatment, yes (\%) & 27 (25.96\%) & $16(31.37 \%)$ & II (20.75\%) & 0.269 \\
\hline \multicolumn{5}{|l|}{ Pulmonary function } \\
\hline FVC in L, median (range) & $\begin{array}{l}2.23(0.72-3.82) \\
n=93\end{array}$ & $\begin{array}{l}2.28(0.98-3.3 \mathrm{I}) \\
\mathrm{n}=50\end{array}$ & $\begin{array}{l}2.18(0.72-3.82) \\
n=43\end{array}$ & 0.437 \\
\hline \%FVC, median (range) & $\begin{array}{l}66.9(20.6-109.7) \\
n=93\end{array}$ & $\begin{array}{l}68.5(37.5-109.7) \\
n=50\end{array}$ & $\begin{array}{l}65.3(20.6-97.2) \\
n=43\end{array}$ & 0.337 \\
\hline DLco in $\mathrm{mL} / \mathrm{min} / \mathrm{mmHg}$, median (range) & $\begin{array}{l}7.19(1.99-16.64) \\
n=81\end{array}$ & $\begin{array}{l}7.39(2.96-14.02) \\
n=44\end{array}$ & $\begin{array}{l}6.26(1.99-16.64) \\
n=37\end{array}$ & 0.488 \\
\hline \%DLco, median (range) & $\begin{array}{l}29.81(8.5-63.5) \\
n=81\end{array}$ & $\begin{array}{l}30.92(12.8-57.6) \\
n=44\end{array}$ & $\begin{array}{l}33.70(8.5-63.5) \\
n=37\end{array}$ & 0.779 \\
\hline
\end{tabular}

Abbreviations: P, patients who were able to receive nintedanib for more than 12 months; I, patients who were not able to receive nintedanib for more than 12 months; BMI, body mass index; BSA, body surface area; mMRC, modified Medical Research Council Dyspnea; FVC, forced vital capacity; DLco, diffusing capacity of the lungs for carbon monoxide; PSL, prednisolone. 
Table 2 Major Adverse Effects of Long-Term Nintedanib Treatment

\begin{tabular}{|c|c|c|c|c|}
\hline Adverse Effects & $\begin{array}{l}\text { All Patients } \\
\mathrm{N}=104\end{array}$ & $\begin{array}{l}\text { P Group } \\
n=51\end{array}$ & $\begin{array}{l}\text { I Group } \\
n=53\end{array}$ & $p$-value \\
\hline Diarrhea & $44(42.31 \%)$ & 20 (39.22\%) & $24(45.28 \%)$ & 0.557 \\
\hline Diarrhea $>$ Grade 3 & $18(17.31 \%)$ & 8 (15.69\%) & $10(18.87 \%)$ & 0.667 \\
\hline Nausea/anorexia & $39(37.50 \%)$ & $13(25.49 \%)$ & $26(49.06 \%)$ & 0.012 \\
\hline Nausea/anorexia $>$ Grade 3 & $13(12.50 \%)$ & 2 (3.92\%) & II (20.75\%) & 0.009 \\
\hline Weight loss & $25(24.04 \%)$ & $13(25.49 \%)$ & $12(22.64 \%)$ & 0.820 \\
\hline Weight loss $>$ Grade 3 & $5(4.81 \%)$ & 2 (3.92\%) & $3(5.66 \%)$ & 0.782 \\
\hline Liver dysfunction & II (I0.58\%) & $6(11.76 \%)$ & $5(9.43 \%)$ & 0.699 \\
\hline Liver dysfunction > Grade 3 & $6(5.77 \%)$ & $3(5.88 \%)$ & $3(5.66 \%)$ & 0.926 \\
\hline Pneumothorax & $8(7.69 \%)$ & I (1.96\%) & 7 (13.21\%) & 0.031 \\
\hline Pneumothorax $>$ Grade 3 & $6(5.77 \%)$ & I (1.96\%) & 5 (9.43\%) & 0.039 \\
\hline Bleeding & $9(8.65 \%)$ & $4(7.84 \%)$ & 5 (9.43\%) & 0.773 \\
\hline Bleeding $>$ Grade 3 & $3(2.88 \%)$ & $0(0.00 \%)$ & $3(5.66 \%)$ & 0.076 \\
\hline
\end{tabular}

Abbreviations: P, patients who were able to receive nintedanib for more than 12 months; I, patients who were not able to receive nintedanib for more than 12 months.

monoxide due to a severe cough or hypoxemia. In 39 patients, treatment with nintedanib was started at a dosage of $200 \mathrm{mg} /$ day due to advanced age and/or poor baseline PS. Twenty-seven patients had received low-dose corticosteroid treatment before the nintedanib initiation. Among these patients, 19 received prednisolone due to the interstitial pneumonia progression before nintedanib initiation. In most of these patients, nintedanib treatment was started over a year prior.

Among the 19 patients with corticosteroid initiation, eight patients received steroid treatment by having their pathogenesis of interstitial pneumonia associated with auto-immune features. However, these patients were not diagnosed with any auto-immune diseases; therefore, the clinicians considered the diagnosis as idiopathic interstitial pneumonias, particularly IPF, and initiated nintedanib.

The other 11 patients had received small amounts of corticosteroids a long time prior to the publishing of the international IPF treatment statement.

Among the remaining eight patients, corticosteroid treatment was initiated in five for drug-induced lung toxicity superimposed on IPF. The other three patients were treated with prednisolone for diseases in organs other than the lung. Sixteen patients who initiated a full dose of nintedanib experienced dose reduction to $200 \mathrm{mg}$ of nintedanib. Four patients previously received pirfenidone and changed from pirfenidone and nintedanib. Three patients changed the anti-fibrotic agents from nintedanib to pirfenidone due to adverse effects. There was no significant difference in the treatment methods between the two groups.

PS level in the P group was significantly higher than in the I group $(p=0.0003)$, and age in the $\mathrm{P}$ group tended to be higher than that in the I group $(p=0.056)$. However, there was no significant difference in the other patient characteristics, particularly GAP index and mMRC, pulmonary function test results, the frequency of corticosteroid use, and nintedanib initiation dosage between the two groups.

\section{Adverse Effects of Continuable Treatment with Nintedanib Over 12 Months}

The major adverse effects associated with long-term nintedanib treatment are shown in Table 2. The incidences of diarrhea, nausea, weight loss, and liver dysfunction were $42.31 \%, 37.50 \%, 24.04 \%$, and $10.58 \%$, respectively. The incidence of nausea $(25.49 \%$ vs $49.06 \%, p=0.012)$ and pneumothorax $(1.96 \%$ vs $13.21 \%, p=0.031)$ were significantly higher in the I group than in the P group. However, there were no significant differences in other adverse effects between the two groups. 
A

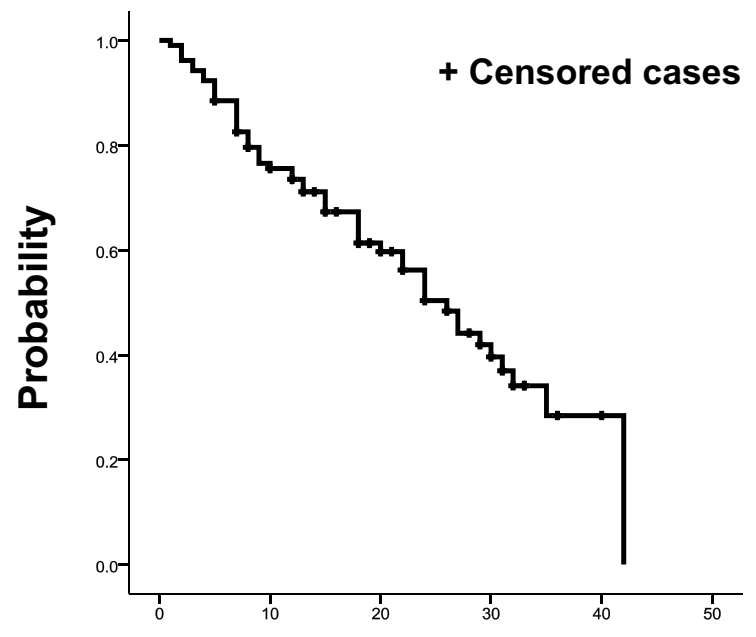

Survival time (months)
B

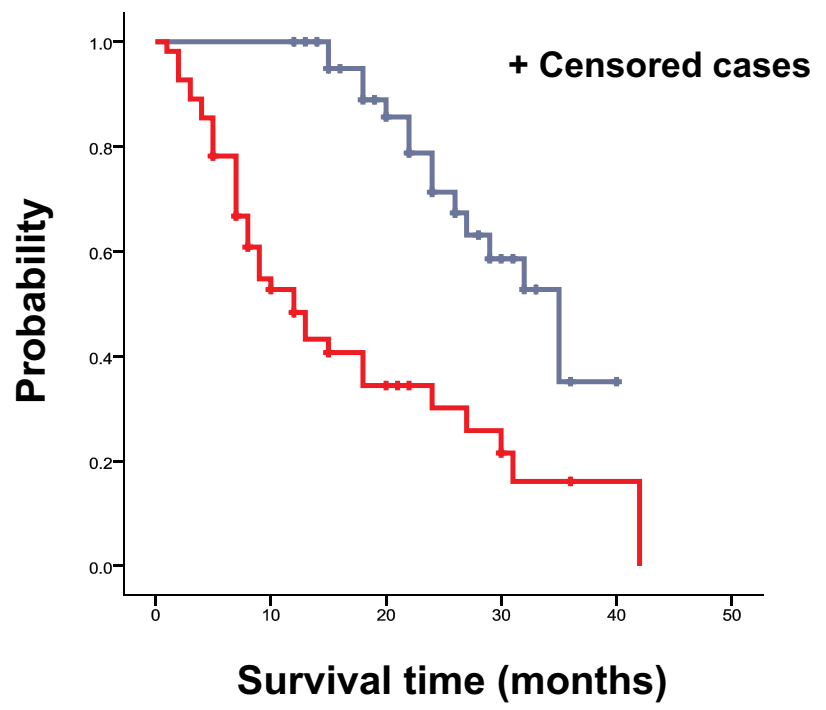

Figure 2 The time from the initiation to the end of nintedanib treatment. (A) All patients. (B) Patients who were (P group: blue line) and those who were not (I group: red line) able to receive nintedanib for more than 12 months. The $p$-value was calculated using the Log rank test.

A

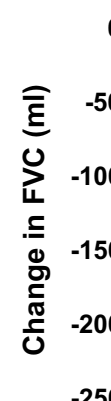

$-250$
B

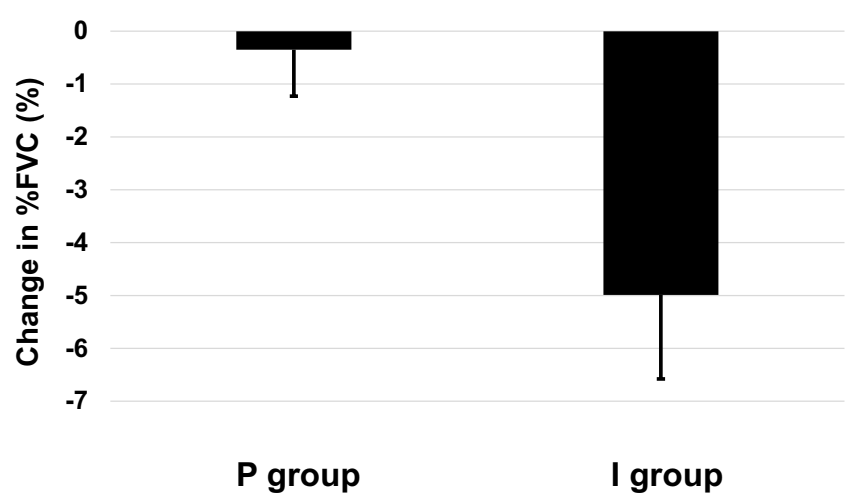

Figure 3 The annual change in forced vital capacity (FVC). The difference in the annual change in (A) FVC volume (mL) and (B) \%FVC between the I and the P groups. The p-value was calculated using the Log rank test.

\section{Effect of Nintedanib on Survival, Changes} in Forced Vital Capacity, and Inhibition of Acute Exacerbation

We evaluated the effect of nintedanib on the survival time from the initiation of nintedanib and inhibition of the development of acute exacerbation. The survival curve for all patients who received nintedanib is shown in Figure 2A. The median survival time was 26 months from the initiation of nintedanib $(95 \%$ confidence interval [CI]: 21.101-30.899). The survival curves for the $\mathrm{P}$ and I groups are shown in Figure 2B. The median survival time in the I group was significantly shorter than that in the $\mathrm{P}$ group (12 months [95\% CI: 8.097-15.903] vs 35 months [95\% CI: 27.031-42.969]; hazard ratio: 26.148, $p=0.001)$.

Next, we compared the annual FVC change between the two groups. The median annual FVC decline in the I group was significantly larger than in the $\mathrm{P}$ group $(165 \mathrm{~mL} / \mathrm{year}, \mathrm{n}=$ 16 vs $10 \mathrm{~mL} /$ year, $\mathrm{n}=37 ; p=0.028$; Figure 3A). Moreover, the median annual decline in $\% \mathrm{FVC}$ in the I group was significantly greater than that in the $\mathrm{P}$ group $(4.99 \% /$ year, $\mathrm{n}=16$ vs $0.35 \% \mathrm{~mL} /$ year, $\mathrm{n}=37 ; p=0.012$; Figure $3 \mathrm{~B}$ ). 
Table 3 Risk Factors for Discontinuing Nintedanib Treatment After 12 Months

\begin{tabular}{|l|l|l|l|}
\hline Variables & OR & 95\% Cl & -value \\
\hline Age & 0.452 & $0.042-4.329$ & 0.485 \\
\hline Performance status & 0.014 & $0.002-0.167$ & 0.007 \\
\hline Nausea/anorexia & 2.210 & $0.885-5.664$ & 0.096 \\
\hline Pneumothorax & 5.802 & $0.847-115.806$ & 0.083 \\
\hline
\end{tabular}

Abbreviations: $\mathrm{OR}$, odds ratio; $\mathrm{Cl}$, confidence interval.

Then, we evaluated the difference in the frequency of IPF acute exacerbation between the $P$ group and the I group. The frequency of acute exacerbation in the I group tended to be higher than in the P group $(16.98 \%$ vs $5.88 \% ; p=0.076)$.

\section{Risk Factors for Nintedanib Treatment Discontinuation Within 12 Months}

We performed multivariate analysis to determine the risk factors for nintedanib treatment discontinuation within 12 months using the following four variables: age, PS, development of nausea, and development of pneumothorax. Poor PS was the only significant risk factor for nintedanib treatment discontinuation after 12 months (Table 3).

Finally, we analyzed the difference in the survival time between patients with poor PS and with good PS. The

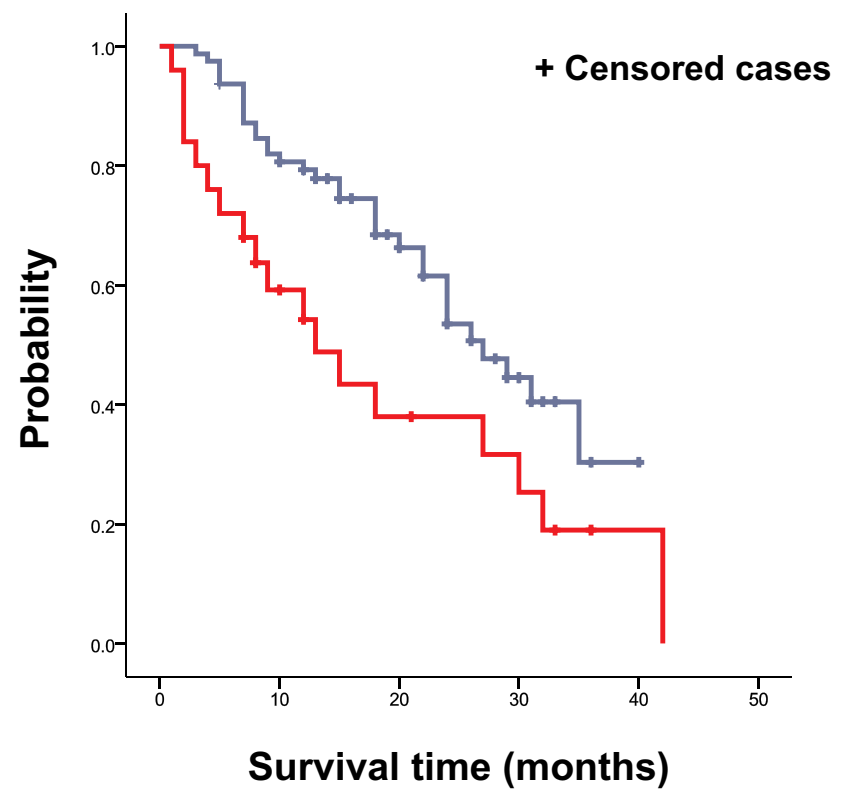

Figure 4 The difference in survival probability since the initiation of nintedanib therapy in patients with poor PS (red line) and good PS (blue line). survival time was significantly longer in the good PS group (27 months, 95\% CI: 21.034-32.966) than in the poor PS group (13 months, 95\% CI: 5.098-20.902; hazard ratio: $5.834, p=0.016$; Figure 4 ).

\section{Discussion}

To our best of our knowledge, this is the first study to report the tolerability and efficacy of nintedanib in realworld clinical practice. The five main findings of this study are as follows: first, the frequency of discontinuation of nintedanib treatment after 12 months in patients with poor PS, nausea/anorexia, or pneumothorax was lower than that in those with good PS, or no nausea/anorexia or pneumothorax. Second, poor PS was the only identified risk factor for early discontinuation of nintedanib treatment. Third, annual FVC decline was significantly associated with early discontinuation of nintedanib treatment. Fourth, the survival time was significantly shorter in the I group than in the $\mathrm{P}$ group. Fifth, the survival time in patients with good PS was significantly longer than that in patients with poor PS.

We previously reported that PS is an important factor for the development of adverse effects associated with nintedanib, particularly diarrhea and nausea. ${ }^{13}$ PS was not focused on the evaluation of anti-fibrotic treatment as opposed to that of anti-cancer treatment; however, nintedanib was initially developed as an anti-cancer agent. Thus, we evaluated the anti-fibrotic treatment for the risk factors of adverse effects in nintedanib treatment. Further, Oishi et al demonstrated that poor PS is a risk factor for both nintedanib and pirfenidone treatment discontinuation. ${ }^{8}$ Nintedanib and pirfenidone have different mechanisms of action. Nintedanib targets three tyrosine kinase receptors (vascular endothelial growth factor receptor, platelet-derived growth factor receptor, and fibroblast growth factor receptor) ${ }^{19}$ and was originally developed as an anti-cancer agent. ${ }^{20-22}$ In contrast, pirfenidone was developed as an anti-inflammatory medicine; the mechanism of pirfenidone remains unknown. Although the effect of both anti-fibrotic agents is similar, their toxicity is different. Therefore, in the future, we should also evaluate pirfenidone. In this study, we showed that poor PS was the risk factor for nintedanib treatment discontinuation after 12 months, similar to the previous report. ${ }^{8}$ Thus, the study by Oishi et al supports our conclusion that PS might be very important for continuable treatment with nintedanib over 12 months. PS is known as a general condition in patients with any cancer; however, PS has 
not been generally used for the evaluation of the general condition of patients with interstitial pneumonia since there is some evidence that PS is associated with general condition in interstitial pneumonia. Nintedanib is known as an anti-fibrotic agent, which was originally developed as an anti-cancer agent; therefore, it may be important to use PS for the evaluation of general condition during antifibrotic therapy. Although a few studies have reported that PS is used for the evaluation of the general condition for anti-fibrotic therapy, there is not enough evidence for evaluation of the general condition using PS. Therefore, even analyzing data from retrospective studies may be important for the evaluation of interstitial pneumonia.

Anorexia and nausea are known adverse effects of nintedanib. In our previous report, the survival time was significantly lower in patients who developed nausea than in patients without nausea. However, we could not identify the reason why the patients with nausea had poor prognosis. ${ }^{13}$ In this report, although nausea/anorexia was not a risk factor for nintedanib treatment discontinuation within 12 months, the frequency of nausea/anorexia was significantly higher in the I group than in the P group. Further, we demonstrated that the annual FVC decline was significantly larger in the I group than in the $\mathrm{P}$ group; therefore, there might be an association among incidence of nausea/anorexia, nintedanib treatment discontinuation, and survival.

Among the included patients, 27 patients received corticosteroids prior to the initiation of nintedanib. Treatment with nintedanib was started when the prednisolone dose was less than $15 \mathrm{mg} /$ day. In the clinical trial for nintedanib, ${ }^{2}$ prednisolone ( $15 \mathrm{mg} /$ day or less) could be used in combination with nintedanib. Therefore, there were not many differences between the clinical trial for nintedanib and our data regarding the corticosteroid effect on nintedanib.

We evaluated the pulmonary function in only 16 patients in the I group after initiation of nintedanib because we could not perform pulmonary function tests in others due to respiratory symptoms or a poor general condition. FVC decline in the patients who could receive evaluation of pulmonary function in the I group was considered to be greater than that in those who could not continue evaluation of pulmonary function. Therefore, the pulmonary function was considered to be worsening in patients who did not continue receiving nintedanib for more than 12 months than in those who did. In other words, continuable treatment with nintedanib over 12 months may inhibit the progression of worsening pulmonary function.
We also analyzed the data excluding the patients who died within 12 months; however, there were no significant differences in most of the data, including the patients' background characteristics, risk factors associated with early discontinuation of nintedanib, and survival between the original data and the data excluding the patients who died within 12 months.

This study has a few limitations. First, this was retrospective study with a small sample size. Thus, patient characteristics were more heterogeneous than in a prospective clinical trial. Particularly, baseline pulmonary function range was wide in both groups. Therefore, there may be some bias for the evaluation of efficacy of nintedanib for the FVC decline. Second, this was a realworld clinical study; therefore, the baseline general condition and pulmonary function were poorer, and the number of patients who could not continue receiving nintedanib was smaller in this study than in the INPULSIS trial. Further prospective studies with a larger patient number is needed in the future to validate our results. Third, we collected the data of adverse effects every 6 months; therefore, we might have failed to collect some data regarding the development of any adverse effects.

\section{Conclusion}

Our findings propose that a poor PS was the only risk factor for discontinuation of nintedanib treatment after 12 months. Nintedanib treatment discontinuation after 12 months was associated with a decrease in the effect of nintedanib; thus, FVC decline was significantly larger in the I group than in the P group. Previously, we have demonstrated that poor PS is significantly related to the development of gastrointestinal adverse effects, including diarrhea and nausea. Nintedanib treatment should start before PS deteriorates, in other words, before the progression of IPF.

\section{Data Sharing Statement}

All datasets are available from the corresponding author on reasonable request.

\section{Ethics Approval and Consent to Participate}

All procedures performed in studies involving human participants were in accordance with the ethical standards of the institutional and national research committee and with the 1964 Helsinki declaration and its later amendments or comparable ethical standards. This study protocol was approved 
by Juntendo University's ethics committee (number 18-056). The ethics committee waived the requirement for informed consent by the retrospective study.

\section{Acknowledgments}

We would like to thank Editage for English language editing.

\section{Funding}

There is no funding to report.

\section{Disclosure}

Motoyasu Kato served as the speaker for Boehringer Ingelheim and reports personal fees from speaker honoraria, outside the submitted work. Kazuhisa Takahashi reports donation from Boehringer Ingelheim, during the conduct of the study. The authors report no other potential conflicts of interest for this work.

\section{References}

1. Richeldi L, Costabel U, Selman M, et al. Efficacy of a tyrosine kinase inhibitor in idiopathic pulmonary fibrosis. $N$ Engl $J$ Med. 2011;365:1079-1087. doi:10.1056/NEJMoa1103690

2. Richeldi L, Du Bois RM, Raghu G, et al. Efficacy and safety of nintedanib in idiopathic pulmonary fibrosis. $N$ Engl $J$ Med. 2014;370:2071-2082. doi:10.1056/NEJMoa1402584

3. Richeldi L, Cottin V, Du Bois RM, et al. Nintedanib in patients with idiopathic pulmonary fibrosis: combined evidence from the TOMORROW and INPULSIS ${ }^{\circledR}$ trials. Respir Med. 2016;113:74-79. doi:10.1016/j.rmed.2016.02.001

4. Azuma A, Taniguchi H, Inoue Y, et al. Nintedanib in Japanese patients with idiopathic pulmonary fibrosis: a subgroup analysis of the INPULSIS $^{\circledR}$ randomized trials. Respirology. 2017;22(4):750-757. doi: $10.1111 /$ resp. 12960

5. Crestani B, Huggins JT, Kaye M, et al. Long-term safety and tolerability of nintedanib in patients with idiopathic pulmonary fibrosis: results from the open-label extension study, INPULSIS-ON. Lancet Respir Med. 2019;7(1):60-68. doi:10.1016/S2213-2600(18)30339-4

6. Song JW, Ogura T, Inoue $Y$, et al. Long-term treatment with nintedanib in Asian patients with idiopathic pulmonary fibrosis: results from INPULSIS ${ }^{\circledR}$-ON. Respirology. 2020;25(4):410-416. doi:10.1111/ resp. 13647

7. Richeldi L, Kreuter M, Selman M, et al. Long-term treatment of patients with idiopathic pulmonary fibrosis with nintedanib: results from the TOMORROW trial and its open-label extension. Thorax. 2018;73(6):581-583. doi:10.1136/thoraxjnl-2016-209701

Drug Design, Development and Therapy

\section{Publish your work in this journal}

Drug Design, Development and Therapy is an international, peerreviewed open-access journal that spans the spectrum of drug design and development through to clinical applications. Clinical outcomes, patient safety, and programs for the development and effective, safe, and sustained use of medicines are a feature of the journal, which has also
8. Oishi K, Hirano T, Murata Y, et al. Medication persistence rates and predictive factors for discontinuation of antifibrotic agents in patients with idiopathic pulmonary fibrosis: a real-world observational study. Ther Adv Respir Dis. 2019;13:1753466619872890. doi:10.1177/ 1753466619872890

9. Oku H, Shimizu T, Kawabata T, et al. Antifibrotic action of pirfenidone and prednisolone: different effects on pulmonary cytokines and growth factors in bleomycin-induced murine pulmonary fibrosis. Eur J Pharmacol. 2008;590(1-3):400-408. doi:10.1016/j.ejphar.2008.06.046

10. Inomata M, Nishioka $\mathrm{Y}$, Azuma A. Nintedanib: evidence for its therapeutic potential in idiopathic pulmonary fibrosis. Core Evid. 2015;10:89-98. doi:10.2147/CE.S82905

11. King JT, Bradford WZ, Castro-Bernardini S, et al. A phase 3 trial of pirfenidone in patients with idiopathic pulmonary fibrosis. $N$ Engl J Med. 2014;370:2083-2092. doi:10.1056/NEJMoa1402582

12. Ikeda S, Sekine A, Baba T, et al. Low body surface area predicts hepatotoxicity of nintedanib in patients with idiopathic pulmonary fibrosis. Sci Rep. 2017;7:10811. doi:10.1038/s41598-017-11321-x

13. Kato M, Sasaki S, Nakamura T, et al. Gastrointestinal adverse effects of nintedanib and the associated risk factors in patients with idiopathic pulmonary fibrosis. Sci Rep. 2019;9:12062. doi:10.1038/ s41598-019-48593-4

14. Raghu G, Collard HR, Egan JJ, et al. An official ATS/ERS/JRS/ ALAT statement: idiopathic pulmonary fibrosis: evidence-based guidelines for diagnosis and management. Am J Respir Crit Care Med. 2011;183:788-824. doi:10.1164/rccm.2009-040GL

15. Mahler DA, Wells CK. Evaluation of clinical methods for rating dyspnea. Chest. 1988;93:580-586. doi:10.1378/chest.93.3.580

16. Oken MM, Creech RH, Tormey DC, et al. Toxicity and response criteria of the Eastern Cooperative Oncology Group. Am J Clin Oncol. 1982;5:649-655. doi:10.1097/00000421-198212000-00014

17. Du Bois D, Du Bois EF. A formula to estimate the approximate surface area if height and weight be known. Arch Intern Med. 1916;17:863-871. doi:10.1001/archinte.1916.00080130010002

18. Ryerson CJ, Vittinghoff E, Ley B, et al. Predicting survival across chronic interstitial lung disease: the ILD-GAP model. Chest. 2014;145:723-728. doi:10.1378/chest.13-1474

19. Chaudhary NI, Roth GJ, Hilberg F, et al. Inhibition of PDGF, VEGF and FGF signaling attenuates fibrosis. Eur Respir J. 2007;29:976-985. doi:10.1183/09031936.00152106

20. Hilberg F, Roth GJ, Krssak M, et al. BIBF 1120: triple angiokinase inhibitor with sustained receptor blockade and good antitumor efficacy. Cancer Res. 2008;68:4774-4782. doi:10.1158/0008-5472. CAN-07-6307

21. Ellis PM, Kaiser R, Zhao Y, Stopfer P, Gyorffy S, Hanna N. Phase I open-label study of continuous treatment with BIBF 1120, a triple angiokinase inhibitor, and pemetrexed in pretreated non-small cell lung cancer patients. Clin Cancer Res. 2010;16(10):2881-2889. doi:10.1158/1078-0432.CCR-09-2944

22. Reck M, Kaiser R, Eschbach C, et al. A phase II double-blind study to investigate efficacy and safety of two doses of the triple angiokinase inhibitor BIBF 1120 in patients with relapsed advanced non-small-cell lung cancer. Ann Oncol. 2011;22(6):1374-1381. doi:10.1093/annonc/mdq618 management system is completely online and includes a very quick and fair peer-review system, which is all easy to use. Visit http://www. dovepress.com/testimonials.php to read real quotes from published authors.

\section{Dovepress}

